\title{
Polyimide-based Carbon Membrane: Effect of Coating Times on Helium Separations
}

\author{
Muhamad Atif Mohamed ${ }^{1}$, Norazlianie Sazali ${ }^{1,2,{ }^{*}}$ \\ 1 Structural Performance Material Engineering (SUPREME), Faculty of Mechanical \& Automotive Technology Engineering, Universiti Malaysia \\ Pahang, 26600 Pekan, Pahang, Malaysia \\ 2 Centre of Excellence for Advanced Research in Fluid Flow (CARIFF), Universiti Malaysia Pahang, Lebuhraya Tun Razak, 26300 Gambang, \\ Kuantan, Pahang, Malaysia
}

\section{ABSTRACT}

In this study, fabrication of tubular carbon membrane prepared from BTDA-TDI/MDI (P-84) polyimide are investigated. Carbon membrane can be observed as the forthcoming of the separation media in gas separation process due to its tremendous gas separation performance, ease process ability, and conservative energy requirement as compared to conventional separation. The consequences of the dip-coating methods to produce high performance tubular carbon membrane by manipulating the coating times $(15,30,45$, and 60 minutes) which have been identified as an influence on the outcome of dip-coating method. Based on above-mentioned studies, we formulated the hypothesis that tubular carbon membrane performance can be controlled by manipulating the carbonization conditions which was conducted with a heating rate of $3^{\circ} \mathrm{C} / \mathrm{min}$, a final temperature of $800^{\circ} \mathrm{C}$ and stabilization time of $300^{\circ} \mathrm{C}$. Pure gas permeation tests were performed by single gas permeation test at room temperature and at 8 bars. Helium $(\mathrm{He})$, and Nitrogen $\left(\mathrm{N}_{2}\right)$ gas are used to investigate the transport mechanism in the carbon membrane separation process. From this study, the highest selectivities of $305.86 \pm 2.21$ for $\mathrm{He} / \mathrm{N}_{2}$; He permeance of $984.92 \pm 1.65 \mathrm{GPU}$ were achieved by applying 45 minutes coating times.

\section{Keywords:}

Carbon membrane, dip-coating times, BTDA-TDI/MDI(P-84) polyimide, Helium separation

\section{Introduction}

Utilization of membrane in order to separate gas is a dynamic method and currently undergoes expeditious growth in the industry. They received enormous attention because they offer quite a few advantages such as easy to operate due to it having no moving parts, requires low energy and economical for low-scale operation. Gas separation is among the primary applications in membrane technology these days. In the past few years, advancements on gas separation have quicken for gas refining purposes particularly natural gas. Gas separation technology incorporating membrane can be considered as contending gas separation technique in the industry [1-3]. In chemical inertness, helium has high productivity, it is lighter than air property and it able to achieve cryogenic at temperatures that is near to zero degrees. Helium has found in various application in electronic,

\footnotetext{
* Corresponding author.

E-mail address: azlianie@ump.edu.my (Norazlianie Sazali)
} 
industries, and fiber optics fabrication, it acts as a heat transfer agent in rocket technology, and it also used in medical such as MRI scanners [4]. Traditionally, to separate the helium from the natural gas, it need three stage process to purify the helium. The first stage is the initial recovery of helium from natural gas. The next stage is the upgrading of the helium to $70 \%$, and finally is the purification of helium [5]. By virtue of its high condensability, He has higher solubility coefficient compared to other lightweight gases like $\mathrm{H}_{2}, \mathrm{~N}_{2}$ and $\mathrm{CH}_{4}$. Another thing to note, $\mathrm{He}$ has affinity with polar groups for instances carbonyl, ether and acetate groups hence polymer that contains these groups has the possibility to get high selectivity for He [6]. Carbon membranes have desirable features such as outstanding resistance towards heat, exceptional chemical stability even in corrosive environments, great permeability and tremendous selectivity in comparison to polymeric membranes which make them a favourable candidate for gas separation purposes $[7,8]$.

Being one of the possible techniques to isolate He from natural gas, supported carbon membrane has enticed immense attention because it is strong mechanically and has great performance in $\mathrm{He}$ separation. In harsh environments such in the existence of strong acid and base and high temperatures as well as pressures, carbon membranes strive due to their stability. Carbonization of polymeric precursors in regulated inert atmosphere was employed to prepare carbon membranes $[9,10]$, such that the precursor should endure high heat treatment without shrinking excessively and should yield high amount of carbon. The microstructure and gas permeable characteristics of carbon molecular sieve membranes are determined by several parameters in carbonization conditions (heating rate, end temperature, soaking time and gas atmosphere) and pre or post treatment conditions (thermostabilization, oxidation and chemical vapor deposition) [11]. In spite of this, coating techniques are potentially having a role of deciding the final carbon membranes structure given that different time of coating although carbonized in the same conditions will result in different carbon membrane features.

One of the ways to construct carbon membrane is in tubular form in order to diminish flaws and to yield high performance for gas separation [12]. This research study is principally emphasized in providing enhanced understanding on parameters that are appropriate in dip-coating processes in contemplation of controlling the tubular supported carbon membrane morphology. It has been determined that the main parameter has the most influences on the dip-coating process and the said parameter is coating times. On the grounds that there is no impediment in supported size and low utilization of polymers in dip-coating techniques, it appears to have considerable potentiality to be applied in large scale production as well as to take over the current spin coating and spray coating techniques [13]. On the whole, techniques to construct tubular supported carbon membranes described in the literature are complicated while coating times are necessary to expand for obtaining carbon membrane that is free from cracks, which requires several cycle and exceptional attention. The development of membranes without defect by single dipping -drying-carbonization process has only been reported by a few researchers [14-17] however reports on coating are scarce. Defect-free supported carbon membranes were prepared successfully at carbonization end temperatures of 800 ${ }^{\circ} \mathrm{C}(\mathrm{CM}-800)$ and stabilization temperature of $300{ }^{\circ} \mathrm{C}$ (S-CMSM 300) under Argon environment $(200 \mathrm{ml} / \mathrm{min})$. End temperatures for carbonization at $800^{\circ} \mathrm{C}(\mathrm{CM}-800)$, temperature for stabilization at $300{ }^{\circ} \mathrm{C}$ (S-CMSM 300) and Argon environment $(200 \mathrm{ml} / \mathrm{min})$ are the conditions to successfully prepare a defect-free supported carbon membrane. 


\section{Experimental section}

\subsection{Materials}

Chemicals such as polyimide BTDA-TDI/MDI (P-84), polyvinylpyrrolidone (PVP) and microcrystalline were obtained from Sigma Aldrich while N-methyl-2-pyrrolidone (NMP) was acquired from Merck (Germany). These chemicals were utilized as is with no additional purification step. An $8 \mathrm{~cm}$ long porous tubular ceramic support $\left(\mathrm{Al}_{2} \mathrm{O}_{3}\right)$ was bought from Shanghai Gongtao Ceramics Co., Ltd. It has $0.2 \mu \mathrm{m}$ average pore size, inner and outer diameter of $10 \mathrm{~mm}$ and $13 \mathrm{~mm}$ respectively as reported from previous study [10].

\subsection{Preparation of carbon membrane}

Preparation of polymer solution was done under continuous stirring at $80^{\circ} \mathrm{C}$ and it contained $15 w t . \%$ of P-84 in NMP. In order to eliminate trapped bubbles in the solution, sonication was performed and the solution was let to rest for 12 hours. Plunged the tubular support into the polymer solution prepared earlier for 45 minutes and allowed it to go through aging at $80{ }^{\circ} \mathrm{C}$ for 24 hours. Immersed the membranes in methanol for 2 hours then rested them inside an oven for 24 hours long and temperature of $100{ }^{\circ} \mathrm{C}$. Carbon membranes were produced from carbonized polymeric membranes. In order to go through carbonization process, the supported polymeric membranes were positioned at the centre of Carbolite horizontal tubular furnace. Throughout the whole process of carbonization, $3^{\circ} \mathrm{C} / \mathrm{min}$ heating rate was enforced as per reported by previous study [18]. Temperature of the processed membranes was then decreased to room temperature naturally upon the end of every heating cycle.

\subsection{Preparation of carbon membrane}

Carbon tubular membranes have been experimented in the gas permeation system as depicted in our preceding study [19]. The carbon tubular membrane was mounted inside a $14 \mathrm{~cm}$ long stainless-steel tubular frame. With the aim of avoiding leakages while housing the membrane inside the module, the membrane was equipped with rubber O-rings. To calculate the membranes permeance, $P / I$ (GPU) and the membrane selectivity, $\alpha$, these equations were used:

Permeance, $\mathrm{P}$ :

$$
(P / l)_{i}=\frac{Q_{i}}{\Delta p \cdot A}=\frac{Q}{\eta \pi D l \Delta P}
$$

Selectivity, $\alpha$ :

$\alpha_{A / B}=\frac{P_{A}}{P_{B}}=\frac{(P / l)_{A}}{(P / l)_{B}}$

where $P / l$ is the membrane permeance, $Q i$ is the gas i volumetric flow rate at standard temperature and pressure $\left(\mathrm{cm}^{3}(\mathrm{STP} / \mathrm{s}), p\right.$ is the difference of pressure between feed and permeation sides of membrane $(\mathrm{cmHg}), A$ is the surface area of membrane $\left(\mathrm{cm}^{2}\right), n$ is the fibers quantity in the module, $D$ is the membrane outer diameter $(\mathrm{cm})$, and $l$ is the effective membrane length $(\mathrm{cm})$. Definition of selectivity can be described as the permeation ratio of fast gas permeation to slow gas permeation. 


\section{Results and Discussion}

In dip-coating procedure, it has been found that in this type procedures might have extremely recommended to some of application due to their relative simplicity. The transfer properties of the carbon membranes are influence by the coating parameters [20]. By manipulating the coating cycles, it has created a high solidness of carbon membrane while manipulating the coating time it enhances the membrane selectivity and the porousness of the membranes decrease. Along the dip coating process, one way to retrain the development of complicates structure is by interfacial stress among polymer and aiding that reduce the Tg of polymer [21]The distinction of the microstructure if carbon happened due to the dissimilar at the homogeneous polymer surface and it happened during the carbonization process [21].

\subsection{Effects of coating times on gas permeation properties}

Gas separation performance for some gases at room temperature for membranes attained at various time of coating are shown in Table 1. Membrane that has been processed through dip coating procedure has highest selectivity against all other samples in 45 minutes coating time. This owes to the fact that this coating condition caused its pinholes to be well sealed and the penetrate across pores of the membrane was complete [22]. Altogether, the performance was descending in the sequence of $45,60,30$ and 15 minutes. Gas separation performance disparities were decided by carbon microstructure differences which has a direct effect on transport mechanism in membrane. From the result, 45 minutes coating time has high selectivity probably attributable to more pores reduction compared to 60,30 , and 15 minutes coating time. As a matter of fact, the prevalence in transport mechanisms differences is facilitated by pore characteristics differences [23].

Table 1

Gas separation performance of carbon membranes produced from different coating time.

\begin{tabular}{|l|c|c|c|}
\hline \multirow{2}{*}{\begin{tabular}{c}
\multirow{2}{*}{$\begin{array}{c}\text { Sample } \\
\text { (CM-PI) }\end{array}$} \\
\cline { 2 - 4 }
\end{tabular}} & He & $\mathrm{N}_{2}$ & Carbon membrane \\
\cline { 2 - 4 } & $704.76 \pm 1.76$ & $2.62 \pm 1.67$ & $\mathrm{He} / \mathrm{N}_{2}$ \\
\hline $\mathbf{1 5}$ minutes & $821.98 \pm 3.21$ & $2.77 \pm 2.17$ & $268.99 \pm 3.22$ \\
\hline $\mathbf{3 0}$ minutes & $984.92 \pm 1.65$ & $3.22 \pm 3.21$ & $296.74 \pm 1.98$ \\
\hline $\mathbf{4 5}$ minutes & $795.66 \pm 2.74$ & $2.86 \pm 1.28$ & $305.86 \pm 2.21$ \\
\hline $\mathbf{6 0}$ minutes & & & $278.20 \pm 1.72$ \\
\hline
\end{tabular}

Coating time of 45 minutes has evidently higher gas separation performance than the rest of the samples from different coating times due to enhanced carbon membranes morphology [24]. Furthermore, it provides enough time for surface condition improvement as well as for cracks adjustment on extremely porous substrate produced via particle-stabilized direct forming approach. In favour of producing a preeminent material with extremely porous core but comparatively fewer pores on the surface, improvements made on the supported surface resolve around filling in heterogenous defects and mending cracks which then elevate substrate's compressive strength and debris resistance. Nevertheless, the presented method can be assured in pursuance of attaining 
competitive membranes for gas separation. 60 minutes of coating times show reduction on selectivity reading due to the sample exceed the accurate time for surface condition development.

\section{Conclusions}

Based on this study, it is being investigated to find out the influence of coating time for dipcoating method on Polyimide carbon membrane. From this investigation, it shows that the optimum coating time for superior gas separation is at 45 minutes. It is show that the highest selectivities of $\mathrm{He} / \mathrm{N}_{2}$ is $305.86 \pm 2.21$ and the Helium permeance achieved with value of $984.92 \pm 1.65 \mathrm{GPU}$.

\section{Acknowledgement}

Authors would like to extend their gratitude to Ministry of Higher Education Malaysia and Universiti Malaysia Pahang (UMP) with grant number RDU190379.

\section{References}

[1] Baker, Richard W. "Future directions of membrane gas separation technology." Industrial \& engineering chemistry research 41, no. 6 (2002): 1393-1411.

https://doi.org/10.1021/ie0108088

[2] Castel, Christophe, and Eric Favre. "Membrane separations and energy efficiency." Journal of Membrane Science 548 (2018): 345-357.

https://doi.org/10.1016/j.memsci.2017.11.035

[3] Kim, Seong-Joong, Pyung Soo Lee, Jong-San Chang, Seung-Eun Nam, and You-In Park. "Preparation of carbon molecular sieve membranes on low-cost alumina hollow fibers for use in $\mathrm{C} 3 \mathrm{H} 6 / \mathrm{C} 3 \mathrm{H} 8$ separation." Separation and Purification Technology 194 (2018): 443-450.

https://doi.org/10.1016/j.seppur.2017.11.069

[4] N Sazali, WNW Salleh, MN Izwanne, Z Harun, K Kadirgama, Precursor selection for carbon membrane fabrication: a review. Journal of Applied Membrane Science \& Technology 22 (2) 9, $2018 . \quad$ DOI: https://doi.org/10.11113/amst.v22n2.122

[5] Scholes, Colin A., and Ujjal K. Ghosh. "Review of membranes for helium separation and purification." Membranes 7, no. 1 (2017): 9. https://doi.org/10.3390/membranes7010009

[6] Mokhatab S, Poe WA, Mak JY. Chapter 12 - Nitrogen Rejection and Helium Recovery. In: Mokhatab S, Poe WA, Mak JY, editors. Handbook of Natural Gas Transmission and Processing (Fourth Edition): Gulf Professional Publishing; 2019. p. 395-408.

https://doi.org/10.1016/B978-0-12-815817-3.00012-5

[7] Hamm, Janice BS, Alan Ambrosi, Julia G. Griebeler, Nilson R. Marcilio, Isabel Cristina Tessaro, and Liliane D. Pollo. "Recent advances in the development of supported carbon membranes for gas separation." International Journal of Hydrogen Energy 42, no. 39 (2017): 24830-24845.

https://doi.org/10.1016/j.ijhydene.2017.08.071

[8] Haider, Shamim, Arne Lindbråthen, Jon Arvid Lie, Ingerid Caroline Tvenning Andersen, and May-Britt Hägg. "CO2 separation with carbon membranes in high pressure and elevated temperature applications." Separation and Purification Technology 190 (2018): 177-189.

https://doi.org/10.1016/j.seppur.2017.08.038

[9] Ismail, N. H., W. N. W. Salleh, N. Sazali, A. F. Ismail, N. Yusof, and F. Aziz. "Disk supported carbon membrane via spray coating method: Effect of carbonization temperature and atmosphere." Separation and Purification Technology 195 (2018): 295-304.

https://doi.org/10.1016/j.seppur.2017.12.032

[10] N Sazali, WNW Salleh, AF Ismail, NH Ismail, N Yusof, F Aziz, J Jaafar. Influence of intermediate layers in tubular carbon membrane for gas separation performance. International Journal of Hydrogen Energy 44 (37), 20914-20923 8, 2019. https://doi.org/10.1016/j.ijhydene.2018.06.148.

[11] Salleh, W. N. W., and A. F. Ismail. "Effects of carbonization heating rate on CO2 separation of derived carbon membranes." Separation and purification technology 88 (2012): 174-183.

https://doi.org/10.1016/j.seppur.2011.12.019 
[12] Lee, Pyung-Soo, Daejin Kim, Seung-Eun Nam, and Ramesh R. Bhave. "Carbon molecular sieve membranes on porous composite tubular supports for high performance gas separations." Microporous and Mesoporous Materials 224 (2016): 332-338.

https://doi.org/10.1016/j.micromeso.2015.12.054

[13] Kargari, Ali, Ahmad Arabi Shamsabadi, and Masoud Bahrami Babaheidari. "Influence of coating conditions on the $\mathrm{H} 2$ separation performance from $\mathrm{H} 2 / \mathrm{CH} 4$ gas mixtures by the PDMS/PEI composite membrane." International Journal of Hydrogen Energy 39, no. 12 (2014): 6588-6597.

https://doi.org/10.1016/j.ijhydene.2014.02.009

[14] Ismail, N. H., W. N. W. Salleh, N. Sazali, and A. F. Ismail. "Development and characterization of disk supported carbon membrane prepared by one-step coating-carbonization cycle." Journal of industrial and engineering chemistry 57 (2018): 313-321.

https://doi.org/10.1016/j.jiec.2017.08.038

[15] Wang, Chan, Xiaojuan Hu, Jian Yu, Lei Wei, and Yan Huang. "Intermediate gel coating on macroporous Al2O3 substrate for fabrication of thin carbon membranes." Ceramics International 40, no. 7 (2014): 10367-10373. https://doi.org/10.1016/j.ceramint.2014.03.010

[16] Teixeira, Miguel, Sandra C. Rodrigues, Marta Campo, David A. Pacheco Tanaka, Margot A. Llosa Tanco, Luís M. Madeira, José M. Sousa, and Adélio Mendes. "Boehmite-phenolic resin carbon molecular sieve membranesPermeation and adsorption studies." Chemical Engineering Research and Design 92, no. 11 (2014): 2668-2680. https://doi.org/10.1016/j.cherd.2013.12.028

[17] Rodrigues, Sandra C., Roger Whitley, and Adélio Mendes. "Preparation and characterization of carbon molecular sieve membranes based on resorcinol-formaldehyde resin." Journal of Membrane Science 459 (2014): 207-216. https://doi.org/10.1016/j.memsci.2014.02.013

[18] N Sazali, WNW Salleh, AF Ismail, NH Ismail, MA Mohamed, N Nordin. Enhanced gas separation performance using carbon membranes containing nanocrystalline cellulose and BTDA-TDI/MDI polyimide, Chemical Engineering Research and Design 140, 221-228. https://doi.org/10.1016/j.cherd.2018.09.039

[19] N Sazali, WNW Salleh, N Arsat, Z Harun, K Kadirgama, P84 Co-Polyimide-based tubular carbon membrane: effect of pyrolysis temperature. Journal of Applied Membrane Science \& Technology 23 (1), 2019. https://doi.org/10.11113/amst.v23n1.121

[20] Zainal, Wan Nurul Huda Wan, Soon Huat Tan, and Mohd Azmier Ahmad. "Carbon membranes prepared from a polymer blend of polyethylene glycol and polyetherimide." Chemical Engineering \& Technology 40, no. 1 (2017): 94-102. https://doi.org/10.1002/ceat.201500752

[21] Zhang, Cunman, Zhen Geng, and Jianxin Ma. "Self-assembly synthesis of ordered mesoporous carbon thin film by a dip-coating technique." Microporous and mesoporous materials 170 (2013): 287-292. https://doi.org/10.1016/j.micromeso.2012.12.007

[22] Wu, Ting, Merritt C. Diaz, Yihong Zheng, Rongfei Zhou, Hans H. Funke, John L. Falconer, and Richard D. Noble. "Influence of propane on $\mathrm{CO} 2 / \mathrm{CH} 4$ and $\mathrm{N} 2 / \mathrm{CH} 4$ separations in $\mathrm{CHA}$ zeolite membranes." Journal of Membrane Science 473 (2015): 201-209. https://doi.org/10.1016/j.memsci.2014.09.021

[23] Ma, Quan-sheng, Ai-jun Gao, Yuan-jian Tong, and Zuo-guang Zhang. "The densification mechanism of polyacrylonitrile carbon fibers during carbonization." New Carbon Materials 31, no. 5 (2016): 550-554. https://doi.org/10.1016/S1872-5805(16)60031-8

[24] Fuertes, A. B., and T. A. Centeno. "Preparation of supported carbon molecular sieve membranes." Carbon 37, no. 4 (1999): 679-684. https://doi.org/10.1016/S0008-6223(98)00244-9 